\title{
Stance-taking on Brexit in Small Stories on Facebook
}

\author{
Dmytro Poberezhnyi \\ Department of English Philology, V. N. Karazin Kharkiv National University, Kharkiv, Ukraine
}

\begin{abstract}
This paper looks at how the stance of English-speaking Facebook users towards Brexit is actualized in their comments to posts addressing this issue. By using a mixed research approach, which combines narratological analysis of small stories (Georgakopoulou, 2007) with stance-taking theory (Du Bois, 2007), this paper puts to scrutiny 187 small stories which appeared online in January-June 2021. In the focus of attention are verbal and non-verbal stance-taking devices which are analyzed qualitatively and quantitatively. It is shown that both rational and affective stance of anglophone tellers of small stories about Brexit is mostly negative, which can be accounted for by fears and worries caused by the negative trends in home and foreign affairs in the United Kingdom in the post-Brexit period.
\end{abstract}

Index Terms -Brexit, Facebook, post-Brexit, small story, stance (affective, rational), stance-taking

\section{INTRODUCTION}

This paper offers an analysis of stance-taking in small stories found in the English segment of Facebook in commentaries to posts in the post-Brexit period.

In the information society, social networks play a crucial role in the life of people, providing vast opportunities for their personal and professional self-expression as well as their political self-identification. Facebook is a compelling example of that. Having over a billion registered users, it is the most popular social network in the world. As Georgalou aptly remarks (Georgalou, 2015, p. 1), Facebook performs the function of a "cardiograph" of society. This function is evident, inter alia, in how people recount their perceptions of major socio-political events, Brexit being one of them.

The withdrawal of the United Kingdom from the European Union is not a short-time happening, but a long-term process rooted historically in the complex relationship of the United Kingdom with mainland Europe. The growing tension in the relations of the United Kingdom with the European Union resulted in a referendum that took place on June 23, 2016, where the majority of voters expressed their desire for the United Kingdom to leave the European Union. This event is the starting point of the Brexit timeline which ends on December 31, 2020 (https://www.cer.eu/brexittimeline), marking the completion of the transition period and beginning of the post-Brexit one (Gymglish). "PostBrexit" is a new term that has not been universally accepted so far but has already made its way into the present-day public sphere constituted around networks of communication.

Digitalization of interpersonal communication, where two communicants (the addresser and the addressee) keep changing roles on a more or less equal basis, has resulted in the emergence of mass self-communication (Deuze, p. 6) a network that connects many addressers and addresses both live (for example, in a video call) and online (for instance, commenting on someone's post on Facebook). Thus, mass self-communication combines the features of interpersonal and mass communication. The rapid growth of this form of communication caused the appearance of new narrative forms, one of which is a small story. Georgakopoulou defines a small story as a non-prototypical variety of narrative activity, such as tellings of ongoing, future or hypothetical events, which may be known or unknown to the addressee, as well as allusions to tellings and refusals to tell (Georgakopoulou, 2007, p. 148). Small stories differ from the Labovian canonical stories: they typically occur in ordinary conversation and do not have the canonical narrative structure (the beginning, middle, and end) (Georgakopoulou, 2006; Georgakopoulou \& Bamberg, 2005). Being outside the scope of traditional narratological inquiry, small stories are of interest not only to narratologists of functional orientation, but also to communication researchers, psychologists, sociologists, etc.

Small stories about post-Brexit actualize the attitudes of Facebook users to the economic and political changes in the United Kingdom after its decision to leave the European Union entered into force on December 31, 2020. Unlike many traditional media (print and broadcast), Facebook has practically no restrictions for its users to express their stance: comments on Facebook are deleted only in case of extremely obscene language, while the group administration promotes different fields of vision. Stance is understood here after Du Bois (2007) as a linguistically articulated form of social action construed within the broader scope of language, interaction, and sociocultural value.

This research belongs at the intersection of linguo-narratological and communication studies. Its object matter is small stories about Britain's withdrawal from the European Union, more specifically, about the post-Brexit phase of the process. The subject matter is linguistic and extralinguistic means of stance-taking in the small stories under consideration. 
The aim of the analysis is to bring to light the stance-taking means used by tellers of small stories about post-Brexit. In order to achieve this aim, two objectives have been set forth: first, to identify epistemic and affective linguistic and extralinguistic stance-taking means used in small stories about post-Brexit; second, to determine the qualitative characteristics of stance-taking in small stories under analysis.

The paper has a conventional structure. The introduction is followed by a theoretical section, where the notions of narrative, small story, and stance are considered. In the section to follow, the data and methods are described. The next part of the paper presents the main findings and discusses them. The conclusion offers some implications and outlines prospects for further research.

\section{THEORETICAL PREREQUISITES}

Here we consider two main approaches to narrative analysis, specifying the one that this research belongs to, then define the content of the term 'small story', after that, describe how the term 'stance' is treated in modern linguistics and characterize its affective and rational varieties.

Within the structuralist approach (Labov \& Waletzky, 1967), a narrative is defined as a text that portrays events, i.e., changes in some initial state of things. These changes can be external (natural events, social interactions) or internal (mental events). Structuralists take temporality to be the main feature of a narrative, which means that discourse, to be considered a narrative, should be based on some structural scheme that reflects a sequence of events. Narrative blocks (abstract, orientation, complicating actions, evaluation, resolution, and coda) are components of the canonical narrative structure. All kinds of 'deficient' narratives, i.e., the ones that do not have the canonical structure, remain out of the scope of structurally oriented narratological inquiry.

The functionalist approach, which focuses on teleological aspects of discourse, on the contrary, considers that nonprototypical varieties of narratives, small stories in particular, do merit scholarly attention.

Functional theorists postulate the interconnection of the two main functions of language: cognitive and communicative. They recognize that narratives are construed as a kind of interpretative phenomenon, which is a part of the human experience of the world (Fisher, 1987, p. 24; Crites, 1971; Carr, 1997). Consequently, they adhere to the prototypical view on the structure of a category, which presupposes drawing a distinction between the nucleus (the prototypical member) and periphery (marginal members). According to this approach, the prototypical member of the category of narrativity is the canonical story that has a complete set of structural components (abstract, orientation, complicating actions, evaluation, resolution, and coda), while the small story has the status of a peripheral member, which possesses only some of the components, for instance, complicating actions and coda.

Research into small stories is different from the traditional line of inquiry into 'grander' narratives that provide a 'panoramic' view elicited from autobiographies, interviews, etc. The framework for analyzing small stories was suggested by Bamberg (1997) and further developed by his associates (Bamberg \& Georgakopoulou, 2005; Georgakopoulou, 2007, 2013, 2017; Georgalou, 2015). The scholars emphasized the role these stories play in identity construction and positioning (Georgakopolou, 2007, 2014; Sadler, 2018; Page, 2010).

Phylogenetically, people's brains are hardwired for narrative: since time immemorial, a good story has been the best vehicle to share one's idea with another person. Appealing not only to reason, but also to emotions and the subconscious, a narrative connects the situation to numerous contexts (Morozova, 2019, p. 327). Facebook offers its users an opportunity for rich participation in commenting, allowing for narratives to be told by a large number of users in different contextually conditioned Facebook segments, which makes this social network a good source for studying the discourse subject's stance-taking. It is in small stories told in the ongoing user performance on Facebook rather than in canonical narratives that stance-taking is accomplished more effectively.

Du Bois' definition of stance as a linguistically articulated form of social action indicates that stance is contextually dependant, its types are dependent on the situation, time and the place of stance-taking (Du Bois, 2007, p. 139). As universally known, ratio and emotio are two basic spheres of human perception. Thus, stance-taking involves both of them. Researchers (Biber, Finegan, 1989; Biber, 2004; Jaffe, 2009) draw distinction between emotional states ('affective stance') and commitment to the propositional content or degree of reliability ('epistemic stance'). Some scholars also consider as a variety of stance-taking the way something is told, the manner it is linguistically expressed. Such stance-taking acts deal with aesthetic appreciation, emotional effect, as well as moral judgment. This type of stance is rendered by sentence adverbs and is called stylistic stance (Myers, 2003, p. 254). In this article, stylistic stance is taken to be a variety of affective stance.

As for stance components, researchers usually consider them to be as follows: a stance-taker, stance-object, and addressee(s), as well as stance resources like evaluative lexis, modal verbs, punctuation, typography, different languages (Barton, Lee, 2013). Such stance resources as typography and punctuation go under the name of metagraphemics (Baranov, Parshin, 2018). Metagraphemic devices embrace various means of visual transformation of a text using the resources of variability of broadly understood alphabetic writing signs as well as possibilities of semantic interpretation of pictorial components of a text, such as pictures, figures, diagrams, schemes, etc. (Baranov, Parshin, 2018, p. 6).

Metagraphemic devices used on the Internet keep attracting the attention of scholars. For example, the research into the 'Like' feature on Facebook (Barton, Lee, 2013) has shown that this device can be used for many purposes: to express a positive stance but not willing to write a comment, to express interest in some post or its content, to show 
support to the poster, to agree or align with the stance of the status poster, to answer in the affirmative to a question raised in the post, or to indicate that the post has been read.

Stance-taking in comments to posts on Facebook involves devices of various kinds: reported speech, rhetorical questions, intertextuality, irony, concession, and conversational devices. Stance-taking can be instantiated with the help of different grammatical constructions: verb and clause complement, adverbial constructions, modal and semi-modal verbs, and even separate sentences (Myers, 2010).

\section{DATA AND METHODS}

The synergetic and interdependent nature of small stories is determined by the architectural specificity of threads on Facebook, which can be observed within a particular post or page, as well as between several comments. This synergy is supported by the 'reply' and 'time stamp' Facebook features.

The 'reply' feature shows how a small story can be coreferential with: 1) the initial small story contained within the post; 2) a thread of small stories to which it is a reply; 3) another small story to which it is a reply. For instance, the post in Fig. 1 refers to the initial small story - "Whoops a daisy. Bye bye business ". Each small story that appears in the comments to this post will be thematically related to the initial small story.

Since a user can reply to a specific small story causing a thread of small stories to emerge, there is a certain unity between small stories within a thread, as Fig. 1 illustrates. In this thread, there are three comments, which contain three stories addressing the same topic.

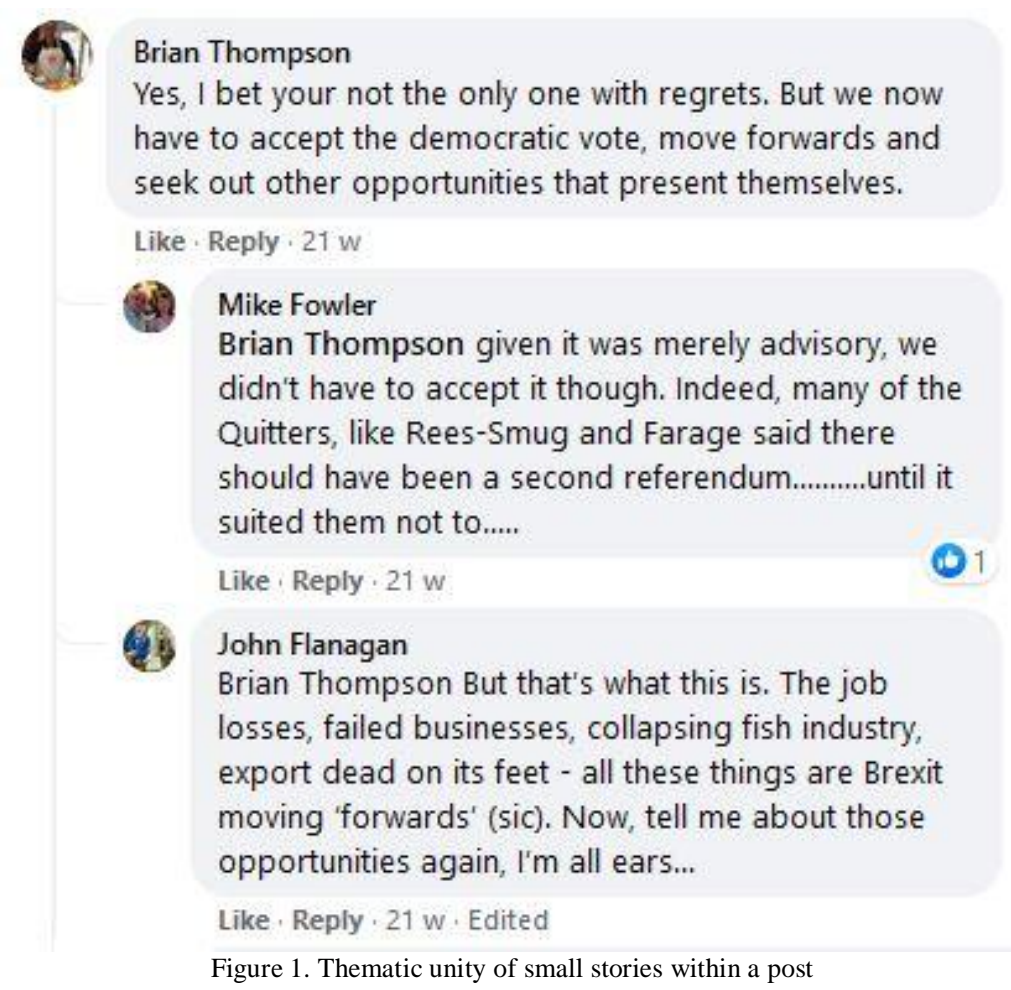

Thematic unity can be achieved when replying to a specific small story. In the example above, John Flanagan replies to Brian Thompson in the form of a small story, indicating the unity with the initial small story in the thread. The 'timestamp' feature demonstrates how a particular small story affects creation of small stories by other users. When the timestamps of several small stories are closely related in time, it means that the respective users have accessed the post simultaneously and the content of one small story has influenced other(s). In particular, it may concern the message of the small story on the whole or its particular fragment, in which case it may be either mentioned by the user or not. Moreover, the time stamp is an important feature of mass self-communication on the whole. 


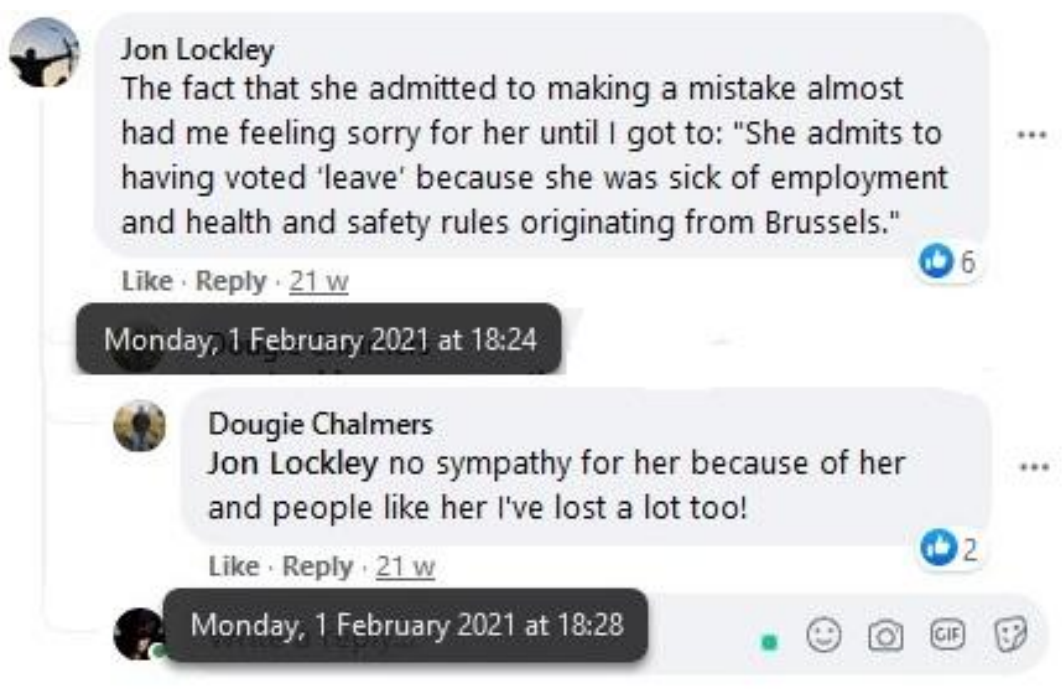

Figure 2. Timestamp feature within a post

Fig. 2 is the example of the timestamp feature showing that time gap between the two small stories is insignificant, thus their thematic bond is stronger.

The dataset of our research comprises 112 discourse fragments that explicate the narrator's stance towards Brexit. They have been selected from 187 small stories told by Facebook users in their comments to three news posts about Brexit in the post-Brexit period. The news posts were published by the community "Very Brexit Problems" (https://www.facebook.com/veryBrexitproblems/posts/).

The descriptive qualitative method applied here aims at comprehensive explanation of stance-taking in small stories in comments to posts on Facebook. The unit of analysis is a synergy of linguistic and metagraphemic means of expressing the narrator's stance. For example, discourse fragments (1) and (2) illustrate stance-taking with the help of textual and metagraphemic means.

(1) Sean Papenfuss

But $i$ thought the EU dictated everything to the countries within, how could they possibly have their own immigration laws $\Theta \Theta \Theta \Theta \Theta$

At least the nhs is booming and the superpower is pushing forwards

The username of the teller is hyperlinked to his personal profile, and thus is given in blue and underscored. The teller neglects some capitalization rules $(i, n h s)$ and punctuation marks (a question mark after the first sentence and a full stop at the end of the second), using emoticons which express their affective stance instead.

(2) Alex MacPhee

I have more respect for someone who made a mistake and admitted it and apologized for, than someone who stubbornly digs in and refuses to face the facts. If this rotten business is ever to be turned round, it will be by getting more people onside, and not by poking people in the eye with a sharp stick and forcing them to be dogs in the manger.

In this comment, the negative rational stance is expressed linguistically by the noun respect.

Thus, a small story in Facebook comments to posts expresses the teller's stance which contributes to their interactional identity. In other words, identity works through positioning of the teller of a small story. As can be seen in examples (1) and (2), the stance of the teller is of interactional nature, expressing their attitude towards the events described in the piece of news posted by somebody else or somebody else's comment.

\section{RESULTS}

As stated above, the notion of stance refers to epistemic or affective components of perception. The epistemic component concerns the origin of the speaker's knowledge about the object of stance-taking (evidentiality) as well as the subjective reflexivity of the current situational context (modality). The affective component relates to the speaker's emotions, feelings, assessments, and attitudes towards the stance object and towards other communicative participants and their stances. As Ushchyna sums up the views of stance researchers, the epistemic stance indicates the speaker's certainty about what is being told, while the affective stance indicates their emotional attitude to it (Ushchyna, 2015, p. 174). In small stories about Brexit that appeared in comments to Facebook posts in the post-Brexit period, both stance types, affective and epistemic, were registered.

As the exchange of comments on Facebook is close to everyday talk, this kind of communication process inherits a number of features of everyday talk, in particular, narrative stance-taking (Georgakopouolou, 2017, p. 316), which is treated as an attested systematic practice for sharing life as breaking news. In other words, in this case, the practice of telling stories becomes a certain stance. For example, selecting certain friends as ratified and primary led to taking a 
narrative stance of a co-produced story (Georgakopouolou, 2017, p. 331). More specifically, narrative stance-taking indicates that an activity is being offered or taken up as a story, thereby positioning participants as tellers-recipients(co)-tellers, etc. and/or consisting of events and characters in specific spatial/temporal scenarios whose actions and speech are assessable.

Taking into account the character of comment-sharing on Facebook is essential to research stance-taking in small stories of post-Brexit. The post under analysis is called "Whoops a daisy. Bye bye business ", which is a small story about the ongoing economic decay occurring because of Brexit. In the picture presented in Fig. 1, one can see two workers employed in the export industry. The workers express their negative stance towards the delays in exporting to Europe non-verbally.

\section{Very Brexit Problems}

Whoops a daisy. Bye bye business

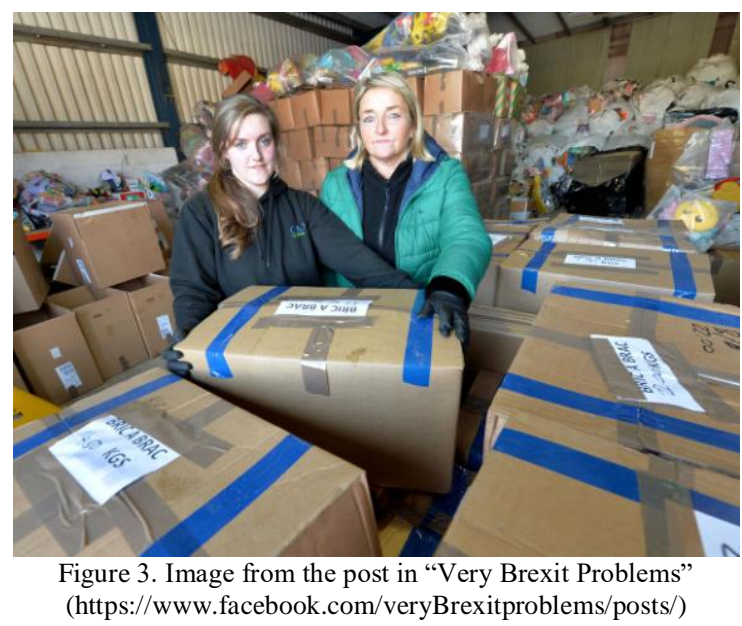

The headline of the post reads: "Whoops a daisy. Bye bye business ". The lead of the article is presented in the following way: "I made a mistake voting for Brexit' says business owner as stock sits waiting to leave warehouse". This information together with the image of the two workers with the dissatisfied facial expression provides a context to the small stories analyzed below.

The post has 557 comments, 187 of which contain small stories reflecting the teller's stance towards the economic changes in the country. Both affective and rational types of stance come in positive and negative varieties. Instantiation of a particular type of stance depends on the teller's approval or disapproval of a situation or viewpoint expressed with the help of different linguistics and / or non-linguistic means.

(3) Helen Edwards Why on earth (1) vote leave when your business exports to Europe. Also note the reasons are Europe dictating employment and H\&S - so someone who would prefer her employees to have fewer rights in terms of employment or H\&S. So now she is drowning in unnecessary red tape. As someone who wanted fewer workers rights as a reason for leaving I find any hard to have any sympathy (2) but at least she has admitted she was wrong, one of the few brexiteers who will do so.

Helen Edward's small story contains two negative affective stance expressions: a rhetorical question (1) and a negation (2).

(4) Tony Clarke $90 \%$ of your business is exported to the EU. And you voted leave (1). Another clear thinking business person. Thanks for all your efforts (2). At least it might be cheaper to sack your poor employees.

The small story by Tony Clarke opens with a negative rational stance expressed with the help of explicating the paradoxical logic of his interlocutor's thinking (1). It is followed by the negative affective stance rendered with the help of two ironic statements (2).

(5) Barry Ellis-Jones

It'll be easier (1) to find business partners who aren't in the U.K. no reason why businesses in the EU will bother with the extra complexity just to deal with us.

Barry Ellis-Jones' positive rational stance-taking in the small story above is expressed with the predicate it'll be easier.

Quite a number of small stories under analysis express stance-taking towards changes in the foreign relations of Great Britain. The main post has the following heading: Just when you think this government can't get any more pathetic

(6) Richard Shannon

No matter how the UK government wants to define the EU, it is how it defines itself and its scope of activity that matters. UK can adopt an aggressive stance towards the EU if it wants, that's the right of any sovereign nation. 
The EU and its predecessors have never been simply a trading bloc, trade was a means to a deeper \& closer relationship between European nations. Perhaps De Gaulle was right back in the 60's that UK has not reconciled itself to no longer being a global imperial power and is therefore unwilling to engage in the European project. And perhaps his assessment remains valid for at least half of UK's population. And in hindsight perhaps the EEC back in the 1970's should have refused UK's application to join, and left UK to face the consequences of lost markets, contracting global relevance and declining industry.

IMO the effect of Brexit is to take UK back to 1969 (1), and to face the very same issues that have largely remained unresolved. What will be the future for UK is anyone's guess but whatever it is it will be nothing like the fantasy of wealth \& power that the Leave campaigners described.

The small story told by Richard Shannon is focused on the political situation caused by Brexit. The teller's negative rational stance (1) is expressed explicitly by a statement that contradicts the present state of affairs.

(7) Sean Papenfuss

But $i$ thought the EU dictated everything to the countries within, how could they possibly have their own immigration laws $\Theta \Theta \theta \Theta \theta(1)$

At least the nhs is booming and the superpower is pushing forwards $\Theta \theta_{(2)}$

The small story by Sean contains the emoticons of 'laughing to tears', which usually signals that someone finds something extremely funny. However, in this case it may also be said to explicate the paradoxical nature of the statements, which can be interpreted as a negative rational stance combined with the negative emotional stance.

(8) Albert Godfrind "She admits to having voted 'leave' because she was sick of employment and health and safety rules originating from Brussels." That says it all.

My answer: you got what you voted for: you are free from the "rules originating from Brussels". And you are also free from your largest export market. Well played!

Albert Godfrind's rational stance is contained in the whole comment. The final sarcastic remark reflects the teller's negative stance towards foreign affairs.

Stance-taking with the help of metagraphemic means is especially vivid in memes and GIF images. One of the popular symbols is the miniature violin, which symbolizes Britain's tragic state.

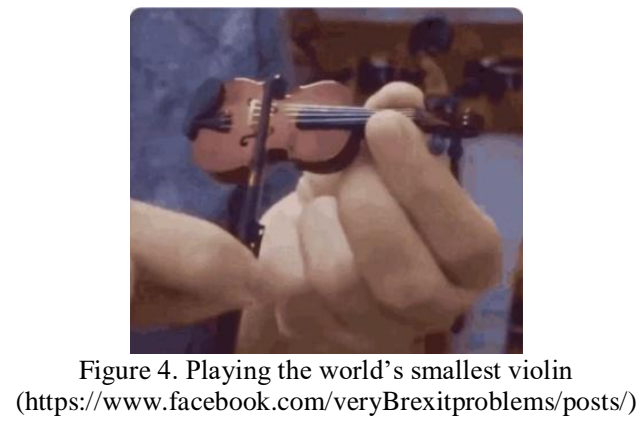

Nero's playing the violin amidst chaos and destruction (https://www.history.com/news/did-nero-really-fiddle-whilerome-burned) has been reflected in numerous violin memes, one of which is presented in Fig. 4. Moreover, the postBrexit phase does not just impede U.K. musicians' freedom to tour in Europe, but also jeopardizes artists' ability to rehearse, as well as blocks the violin trade.

\section{DISCUSSION}

The data contain four types of stance-taking towards post-Brexit: positive epistemic (E+), negative epistemic (E-), positive affective $(\mathrm{A}+)$ and negative affective (A-). The quantitative characteristics of stance-taking means used in small stories of Brexit are summed up in Table 1. 
TABLE 1

LiNGUISTIC MEANS OF STANCE-TAKING

In SMALl STORIES ABout Brexit In THE ANGLOPHONE SEGMENT OF FACEBOOK

\begin{tabular}{|l|l|l|l|}
\hline E+ & E- & A+ & A- \\
\hline need $v$. (3) & affected & serves & stupidity (3) \\
\hline think $v$. (2) & never mind & bright (3) & stupid (3) \\
\hline respect $n$. & made a mistake & right adj. & pesky immigrants \\
\hline suggest & think (8) & & idiot(s) (4) \\
\hline consider & & & fear \\
\hline accurate & & & sad $a d j$. \\
\hline easy (2) & & & damn \\
\hline well played & & & surprise $n$. \\
\hline won & & & lies \\
\hline & & & sympathy (15) \\
\hline & & & should (7) \\
\hline & & & apology \\
\hline & & & happy (3) \\
\hline & & & bleed \\
\hline & & & pathetic \\
\hline & & & too late \\
\hline & & & haha \\
\hline & & & no comment \\
\hline & & & whoops (2) \\
\hline
\end{tabular}

As can be seen in Table 1, positive epistemic stance is found in 13 cases, which is $15,2 \%$ of the total of 78 linguistic means of expressing stance. This type of stance is expressed mostly with verbs.

Negative epistemic stance is found in $13 \%$ of all tokens, most of them being verbs, in particular, the lexeme think.

According to our data, the most representative type of stance-taking is negative affective stance. Unlike epistemic stance, negative affective stance is represented by 27 lexemes with strong negative connotation (bleed, stupid, idiot). The emotional state of the tellers is expressed more vividly with interjections like haha and whoops.

Positive affective stance is found in only $6 \%$ of cases. This type of stance is expressed mostly with adjectives, with the help of which tellers tend to describe their positive feelings and emotions.

It is noteworthy that linguistic means with the positive connotation can be used to express negative stance. For instance, the noun sympathy is widely used in negative constructions, i.e., expresses absence of sympathy towards the post-Brexit situation, which agrees with the general opinion that Brexit has been a wrong decision.

Templeton Blair

Her stupidity cost me my EU citizenship.

Does she want sympathy or forgiveness?

Sharon Rees-Williams

No sympathy ..... it was obviously going to result in this. Should have thought about it before they voted

Danielle Handy Hayden

She voted for it. Suck it up lady. Zero sympathy. My children are now disadvantaged in their future choices involving Europe because of your vote so you can reap what you have sown

Metagraphemic means of stance-taking have turned out to be less representative than linguistic ones (34 discourse fragments). The types of metagraphemic stance-taking included variability of punctuation, ellipsis, and iconic graphemics (pictures, photos, emoticons).

\section{CONCLUSION}

Post-Brexit is a stage of Brexit that triggered a wide response among Facebook users. After the United Kingdom left the European Union, the comments to posts on Facebook evidence the crisis in the economy of the United Kingdom.

Stance is a characteristic feature of small stories that unveils the positioning of the teller. Its analysis in Facebook comments demonstrates that people are prone to utilize Facebook as a powerful narration medium during the postBrexit period, as a channel for telling their small stories: to express fears, share political viewpoints, give insights, evaluate, understand, reflect upon and respond to what is happening.

The analysis of 187 small stories which contain 112 discourse fragments explicating stance, has brought to light 78 tokens of stance expressed linguistically and 34 tokens - with the help of metagraphemic means. The stance-taking analysis has evidenced the representativeness of such types of stance as epistemic positive and affective negative, which indicates that the current situation in the economy and foreign affairs in the United Kingdom is uncertain and has a negative trend.

Affective negative stance followed by the epistemic stance as to the changes in economy may evidence the fears of anglophone Facebook users towards the trade relations between the citizens in the European Union and the United Kingdom to be the most important change for the citizens. Epistemic positive stance towards economic changes follows the two previous ones, which suggests the importance of this sphere for the majority of Facebook users in comparison with other spheres. 
The analysis has demonstrated that Facebook users are frustrated by the economic changes, thus the negative affective type of stance prevails and may be one of the reasons that the social unrest in the United Kingdom persists.

Linguistic means of expressing stance towards post-Brexit on Facebook include verbs, nouns, adjectives, and interjections. The prevailing type of stance is negative affective, expressed mostly by nouns. The verb think is mostly used to express negative rational stance. Adjectives in $75 \%$ cases are used to express negative affective stance. The presence of interjections is episodic and is related to the whole situation described in the article.

Facebook represents stance-rich environment; it combines both linguistic and metagraphemic means. In particular, such metagraphemic means as memes, emoticons, GIF images are the most representative. Ellipsis is used as a nonstandard punctuation mark in place of a period to express uncertainty on the part of the teller.

The Facebook timestamp for each following comment reflects the close time relation (linearity) and the high speed of stance-taking within a small story, which gives grounds to claim the high level of affect in small stories of post-Brexit.

The prospects for further research lie in the study of cumulative effect of linguistic and non-linguistic stance-taking means in the comments to posts on Facebook.

\section{REFERENCES}

[1] Bamberg, M. (2016). Narrative inquiry. Jensen, K.B. \& Kraig, T.T. (Eds.). The International Encyclopedia of Communication Theory and Philosophy. Oxford, UK; Malden, MA: John Wiley and Sons, 1295-1303.

[2] Bamberg, M. (Ed). (1997). Oral versions of personal experience. Mahwah, NJ: Lawrence Erlbaum Associates.

[3] Baranov A.N., Parshin P.B. (2018). O metayazike opisaniya vizualizatsiy teksta (Towards the metalanguage for describing text visualizations). Vestnik VolGU. Ser. 2. Yazikoznaniye. T. 17. No. 3. 6-15.

[4] Barton. D, Lee. C. (2013). Language online: Investigating digital texts and practices. Routledge: London.

[5] Biber D. (2004). Historical patterns for the grammatical marking of stance: A cross-register comparison. Journal of Historical Pragmatics, 5: 107-135.

[6] Biber D., Finegan E. (1989). Styles of stance in English: Lexical and grammatical marking of evidentiality and affect. Text, 9(1): 93-124.

[7] Brockmier, J., Harre, R. (2000). Narrative: problems and promises of an alternative paradigm. Research on Language and Social Interaction, 30(4): 29-42.

[8] Carr, D. (1997). Narrative and the real world: An argument for continuity. Hinchman, L.P., Hinchman, S. (Eds.). Memory, identity, community: The idea of narrative in the human sciences. Albany, NY: State University of New York Press, 7-25.

[9] Crites, S. (1971). The narrative quality of experience. Journal of the American Academy of Religion, 39 (3): 291-311.

[10] Crowley, K. (2018). Memorability in Narration: An Overview of Mnemonic Features in Oral and Written Tradition. Kalbu studijos / Studies about Languages, 32: 77-93.

[11] Deuze, M. (2020). The role of media and mass communication theory in the global pandemic. Communication Today. 11(2): 417.

[12] Du Bois, J. (2007). The stance triangle. R. Englebretson (Ed.). Stance-taking in Discourse. Amsterdam: John Benjamins Publishing Co. 139-182.

[13] Fisher, W.R. (1987). Human communication as narration: Toward a philosophy of reason, value, and action. Columbia, SC: University of South Carolina Press.

[14] Georgakopoulou, A. (2006). Small and large identities in narrative (inter)-action. De Fina, A., Schiffrin, D., \& Bamberg, M. (Eds.). Discourse and identity. Cambridge, UK: Cambridge University Press. 83-102.

[15] Georgakopoulou, A. (2007). Small stories, interaction and identities. Amsterdam: John Benjamins.

[16] Georgakopoulou, A. (2013). Building iterativity into positioning analysis. A practice-based approach to small stories and self. Narrative Inquiry, 23. 89-110.

[17] Georgakopoulou, A. (2017). Sharing the moment as small stories: New challenges. Narrative Inquiry, 27(2). 311-333.

[18] Georgalou, M. (2015). Small narratives of the Greek crisis on Facebook. Social Media + Society, July-December. 1-15.

[19] Gymglish. (2021). Post-Brexit. https://gymglish.com/en/gymglish/english-translation/post-brexit. (accessed 07/7/2021)

[20] Herman, D., Manfred, J., \& Ryan, M.-L. (Eds.). (2005). Routledge Encyclopedia of Narrative Theory. London: Routledge Press.

[21] History. (2021). Did Nero Really Fiddle While Rome Burned? https://www.history.com/news/did-nero-really-fiddle-whilerome-burned. (accessed 02/6/2021).

[22] Jaffe A. (2009). Stance: Sociolinguistic perspectives. Oxford: Oxford University Press.

[23] Kiesling, S.F., Pavalanathan, U., Fitzpatrick, J., Han, X., Eisenstein, J. (2018). Interactional stance-taking in online forums. Computational Linguistics, 44(4). 683-718.

[24] Labov, W., Waletzky, J. (1967). Narrative analysis. Helm, J. (Ed.). Essays on the verbal and visual arts. Seattle: University of Washington Press. 12-44.

[25] Morozova, O. (2019). Ukraine's journey to Europe: strategic macronarrative and conceptual metaphors, European Security, 28:3, 323-340.

[26] Myers, G. (2010). The discourse of blogs and wikis. London: Continuum.

[27] Myers, G. (2013). Stance in Blog. In Hyland, Ken (Ed.), Discourse Studies Readers: Essential Excerpt (pp.254-271). London: Bloomsbury Publishing.

[28] Ochs, E., Capps, L. (2001). Living narrative. Cambridge, MA: Harvard University Press.

[29] Page, R. (2012). Narratives and Social Media: Identities and Interaction. Routledge, New York, NY.

[30] Propp, V. (1927). Morphology of the Folktale. (Trans. by Scott, L.). Austin: University of Texas Press, 1968.

[31] Slipperdisc. (2021). Britain's violin trade blocked by Brexit. https://slippedisc.com/2021/03/britains-violin-trade-is-blocked-bybrexit. (accessed 01/7/2021). 
Dmytro Poberezhnyi was born in Kharkiv, Ukraine in 1994. He obtained his Master's Degree in Foreign Linguistics from V. N. Karazin Kharkiv National University in Ukraine in 2017. Dmytro is currently a PhD student at the Department of English Philology, V. N. Karazin Kharkiv National University. His current research interests include discourse studies and narratology. 